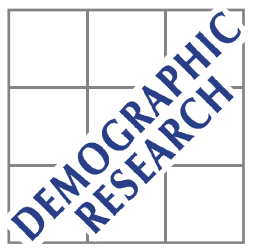

Demographic Research a free, expedited, online journal

of peer-reviewed research and commentary in the population sciences published by the Max Planck Institute for Demographic Research

Konrad-Zuse Str. 1, D-18057 Rostock · GERMANY

www.demographic-research.org

DEMOGRAPHIC RESEARCH

VOLUME 23, ARTICLE 32, PAGES 905-932

PUBLISHED 09 NOVEMBER 2010

http://www.demographic-research.org/Volumes/Vol23/32/

DOI: 10.4054/DemRes.2010.23.32

Research Article

\title{
Asking God about the date you will die: HIV testing as a zone of uncertainty in rural Malawi
}

\section{Amy Kaler}

\section{Susan Watkins}

This publication is part of the proposed Special Collection "HIV/AIDS in subSaharan Africa", edited by Susan Watkins, Jere Behrman, Hans-Peter Kohler, and Simona Bignami-Van Assche.

(C) 2010 Amy Kaler \& Susan Watkins.

This open-access work is published under the terms of the Creative Commons Attribution NonCommercial License 2.0 Germany, which permits use, reproduction \& distribution in any medium for non-commercial purposes, provided the original author(s) and source are given credit. See http:// creativecommons.org/licenses/by-nc/2.0/de/ 


\section{Table of Contents}

1 Introduction $\quad 906$

$2 \quad$ HIV testing and the fight against AIDS 910

3 Data 913

4 Analysis $\quad 914$

$\begin{array}{lll}5 & \text { The badness of testing } & 917\end{array}$

$6 \quad$ The goodness of testing 921

$7 \quad$ When testing is on offer 924

8 Discussion 926

$\begin{array}{lll}9 & \text { Conclusion } & 927\end{array}$

$\begin{array}{ll}\text { References } & 929\end{array}$ 


\title{
Asking God about the date you will die: HIV testing as a zone of uncertainty in rural Malawi
}

\author{
Amy Kaler ${ }^{1}$ \\ Susan Watkins ${ }^{2}$
}

\begin{abstract}
Testing for HIV is becoming more available in Africa. Global advocates of testing see it as key to AIDS prevention. However, testing is not always perceived as a good thing by people at risk. Here, we consider testing from the perspective of people in a highprevalence community. Using qualitative data from rural Malawi, we show that the decision to test is not as straightforward as suggested in the testing advocacy literature, but is marked by uncertainty and ambivalence. Reluctance to test is connected to the perception that testing inevitably leads to a positive diagnosis, and subsequent deterioration and death. This fear is in turn linked to overestimation of the transmissibility of HIV. We recommend that testing advocates address this concern that being tested means having a death sentence pronounced, and emphasize the benefits of testing for the majority who are HIV-negative, as well as the minority who are HIV-positive.
\end{abstract}

${ }^{1}$ University of Alberta. E-mail: akaler@ualberta.ca.

${ }^{2}$ University of Pennsylvania/UCLA. E-mail: swatkins@ccpr.ucla.edu. 


\section{Introduction}

In the past few years testing for HIV has become widely available in sub-Saharan Africa. International organizations and national governments promote testing by making it accessible and free, and by energetic campaigns encouraging citizens to seek it out. From the perspective of testing advocates it is a valuable, even critical, addition to the arsenal of HIV prevention activities. Specifically, proponents of testing expect that those who are positive will be motivated to ensure that they do not transmit their infection to others, while those who learn they are negative will be motivated to be even more risk-averse.

The availability of testing, however, is not always perceived as an unambiguously good thing by the millions in Sub-Saharan Africa who are unaware of their serostatus. People who believe they have never risked infection may see no need for testing, and they may be right. Those who believe they are certain to have contracted the virus may also see no need for testing -- for, in effect, "asking God about the date you will die."

In this paper we consider testing from the perspective of ordinary people in a highprevalence region, the same people whom the global HIV prevention community believes will most benefit from it. Using a set of ethnographic journals written by local field assistants living in rural Malawi, we show that when people talk informally with each other about AIDS, issues of risk, behavior change, and agency are perceived as neither simple nor self-evident, but are marked by great uncertainty. ${ }^{3}$ Neither the public health nor the social science literature deals well with uncertainty. Much like the policy statements disseminated by the global AIDS community and reflected in official Malawian documents, most publications on AIDS in African communities, especially those oriented to influencing programs or policies, produce definite, unequivocal statements. "AIDS orphans are a growing problem in the community" or "young people have negative attitudes towards condom use" (to name two of the current preoccupations in the literature) are presented as unambiguous truths, as certainties. In contrast, the ambivalence and equivocation that we find in AIDS-talk in rural communities in Malawi does not often find expression in policies and programs. Ambivalence and equivocation, however, may be a

\footnotetext{
${ }^{3}$ These data were collected by Susan Watkins as part of the broader project of the Malawi Research Group based at the University of Pennsylvania and directed since 1997 by Susan Watkins, Jere Behrman, Hans-Peter Kohler, Agnes Chimbiri and Eliya Zulu. Details of methodology, including the advantages and disadvantages of our field journals, can be found in [first author] 2004a:287-288 and Watkins and Swidler 2009. We would also like to thank the 22 field assistants who wrote the journals, Davie Chitenje, who paid the assistants, and Jonathan Kandodo, who oversaw the transformation of the handwritten journals into typed texts; Pete Fleming and Kim Yi Dionne for overseeing the transcription, anonymyzing and archiving of the journals; and Patrick Gerland and Nicole Angotti for their helpful comments.
} 
more accurate reflection of the realities of AIDS in rural Malawi than definite and positive statements ${ }^{4}$.

We draw a parallel between responses to HIV testing and previous responses to the epidemic itself, in order to suggest that the uncertainty that now characterizes talk about testing in rural Malawi may come to be resolved. Previous work using ethnographic journals showed that early in the epidemic there was great uncertainty about whether it was possible to prevent HIV by changing one's behavior (Kaler 2004a; Watkins 2004]). ${ }^{5}$ Men in particular appeared to be divided on the question of whether or not behavior change to reduce one's risk of contracting HIV was worth the effort (Kaler 2004a). The effort involved in switching to condom use or struggling against one's desires for sex appeared large to them, and the benefits uncertain, as one might have already contracted the virus from earlier risky sex. In any case it was widely perceived that even those who had so far escaped infection were still likely to die of AIDS, either because HIV infection and death were fated, whether by God or destiny, or because of the power of natural urges.

Subsequently, however, that uncertainty about HIV prevention largely vanished. The possibility of catching HIV and dying has come to be seen as a result of willful disregard of danger - now that everyone knows about HIV and AIDS-related information is everywhere, putting oneself at risk of HIV is a deliberate act, undertaken in full knowledge of the possible consequences. An example illustrates. Here the field assistant and two other men are discussing their lives and loves as they farm:

B. said that ... nine months had passed since he had sex with his sexual partners in Thyolo [a town in the east of Malawi] without using condoms. He said that nowadays he is looking after his life properly and has a healthy life, and if he had already caught it [HIV], let it be the only virus which entered into his body and he didn't want to add [more viruses] for life is so precious nowadays. He said that ... he will not say he is not going to be having sex, but he said he [will be] using 'brake pads' [condoms]!

K. said that taking [getting] AIDS nowadays is by choice. He said that there are lots of messages concerning AIDS and people who follow them are the ones who stay longer in life without dying of it. He continued saying that

\footnotetext{
${ }^{4}$ In a forthcoming dissertation, Nicole Angotti finds that ambivalence and ambiguity characterize Malawians' responses to the international AIDS community insistence that HIV testing regimes observe three norms of testing: that the person to be tested must provide informed consent, that the test and its results must be confidential, and that HIV testing must include pre-test and post-test counseling. (Angotti, N. "Testing Differences: The Implementation of Western HIV Testing Norms in Sub-Saharan Africa," Department of Sociology, University of Texas-Austin, in process.)

${ }^{5}$ Many of these issues have been discussed in previous papers (Kaler 2003, 2004a, 2004b, 2006; Watkins 2004; Smith and Watkins 2005; Kohler, Behrman, and Watkins 2007; Swidler and Watkins 2007; Reniers 2006).
} 
taking AIDS nowadays is by the choice of the man for there are many condoms that are distributed free of charge and if you want to buy them in shops, ... you can afford it, for it's cheap. (Simon 060106).

This transformation in discourse was accomplished through frequent and often intense discussions in local social networks. These interactions with friends, relatives and neighbors now emphasize that prevention is feasible and effective, so much so that speakers criticize those who they believe have contracted AIDS because they ignored the government's prevention messages and the good advice of their friends, relatives and neighbors.

There are, however, new sources of uncertainty. The institutional and therapeutic context has changed, as it has in other high-prevalence countries in sub-Saharan Africa. There are new possibilities for testing and treatment, and new messages announcing that it is important to "know your status" so that you can be counseled on how to "live positively" with HIV. As we will show in this paper these new possibilities and the accompanying directives from the international prevention community and the Government of Malawi have generated new zones of uncertainty. Although talk about testing now displays the ambivalence and equivocation that formerly coalesced around behavior change to prevent infection, that same talk may eventually resolve the uncertainty about testing.

The ethnographic journals show that the existence of testing was a topic of conversation by 2002 . Then it was considered as a theoretically possible course of action, but one that was located in cities, geographically and conceptually distant from everyday life. By 2005 the expansion of testing facilities and the provision of free antiretroviral drugs had made testing and treatment much more concrete. At the same time, however, these new options generated new debates. In the excerpt below, a field assistant overheard two men chatting on a bus. The first man says he is on his way to get a HIV test, the second one postulates a positive HIV diagnosis, the first replies that the advantage of the diagnosis is that one can be advised "on medical grounds" what to do.

The whole story started when these two started to ask each other where they were going. The first gentlemen said he was going to Blantyre to buy goods for his shop while the other one said he was going to Zomba for voluntary counseling and testing.

Then the other man asked him, while puzzled, saying "[why] have one's blood tested, why [not] just staying [without testing]? If one has got HIV/AIDS he will start to get sick, [there is no need] to go and have one's blood tested. ... I cannot go for blood test because once they tell me at the hospital that I am HIV 
positive that means I am already dead and there is nothing I can do in my life because I will know for sure that no matter what, my life is gone, so it is better just to stay without knowing your blood status". His friend [said] "What do you mean by saying once you are found HIV positive you will do nothing?" He answered back confidently "I cannot work hard in everything, like making plans for my future life or doing development work at my home, or finding means to get money ... since I [would] know already that I am HIV positive and dead".

His friend ... shook his head in disagreement. ... "I think you are very much far [away from the truth] in your mind by what you are saying about voluntary counseling and testing. ... Let's suppose one is found with HIV, you are advised on what foods to eat, you are also advised on medical grounds and how you can avoid spreading the disease to others and also how you can avoid increasing the virus in your body just for you to stay long period of time before you die. And if one followed the instructions given at the VCT, he can stay for over twenty years with HIV before he starts suffering and dies, not that once you are found HIV positive it means you're dead". (Chikondi_050212)

Before 2003 none of the field assistants reported more than one or two conversations about testing in a year. These often referred to announcements on the radio or in the newspapers or to people who went to the city, were tested, and died soon after. By 2004 we begin to see more references to relatives and friends in the village who had been tested, and by 2006 we begin to read of people who were once thin and dying of AIDS but are now seen to be plump and healthy due to the new medicines.

Before presenting further local perspectives on testing, we briefly describe the perspectives of the global AIDS community and the Government of Malawi, followed by a description of our data and analytic methods and then our analysis. We show that there is considerable uncertainty about testing in rural Malawi, both within individuals who are ambivalent about the goodness of testing and across the wider community, as some argue for testing and others against it. As testing becomes more ordinary we expect that the discourse in local social networks about the "goodness of testing" and "the badness of testing" will change, just as earlier uncertainty about the possibility of behavior change has largely been resolved in these communities. Our larger, and we believe more generalizable point, is that what appear to distant advocates as certainties may not be perceived as certain by the recipients of their advice. Thus programs and policies based on confident assertions may not be as effective as those that identify and respond to evidence of uncertainty. 


\section{HIV testing and the fight against AIDS}

The vast expansion of opportunities for Voluntary Counseling and Testing (VCT) in rural Malawi is a consequence of the prominence of advocates of VCT in the global AIDS prevention community and the response of international donor organizations to advocates' calls for vastly increased funding. The public statements promoting testing are confident, just as earlier calls for behavior change through abstinence, fidelity and condom use had been. The World Health Organization has made testing the first of its strategic priorities for tackling HIV, ahead of prevention, treatment expansion, strengthening national health systems and better epidemiological information (WHO 2007). In 2003 Kevin DeCock, director of the WHO Department of HIV/AIDS, declared that "Universal voluntary knowledge of HIV serostatus should be a prevention goal" and that "facilitation of HIV testing is central to responding effectively to the epidemic in Africa" (DeCock et al. 2003:1847). Shortly thereafter UNAIDS and WHO issued a joint statement on testing, asserting that "among the interventions that play a pivotal role in both prevention and treatment, testing and counseling stand out as paramount" (UNAIDS/WHO 2004). This position on the critical importance of testing has been maintained up to the present, as in UNAIDS' recent policy brief on testing:

UNAIDS and WHO are supporting a major expansion of access to HIV testing and counseling through the scaling up of client-initiated testing and counseling services and through the expansion of provider-initiated testing and counseling services in health care settings. Such efforts are not only necessary to improve the health of individuals, they are also necessary to achieve universal access to prevention, treatment, care and support and to mount effective responses against HIV. (UNAIDS 2008)

The Gates Foundation, the largest funder of HIV programming in the world, has called for expansion of testing to be an integral part of scaling-up treatment, and leading multilateral organizations have concurred (GHPWG 2004).

Many African leaders in AIDS prevention have also publicly expressed great confidence in the expansion of testing. Karim, Karim, and Baxter, for example, argue with no caveats that testing should be the cornerstone of a comprehensive AIDS prevention and treatment program for South Africa (Karim et al. 2003:1499). In South Africa, AIDS organizations even launched a national contest to win 100,000 Rand, which required proof of testing to enter.

The Government of Malawi echoed such calls for increased testing even before testing facilities were available to the $85 \%$ of the population that lives in the rural areas. Long before rural Malawians could have a reasonable hope of getting tested, after 
attending a United Nations summit on AIDS the Minister of Health distributed a press release saying that VCT must be available and accessible to all (Banda 2001). In Malawi's application to the Global Fund for AIDS, Tuberculosis and Malaria, VCT was justified as seen as a basis for entry into support services for those with AIDS, but also as "...a strategy for change of sexual lifestyle for the prevention of HIV infection...." (Republic of Malawi n.d.: 24).

The media brought VCT to the attention of citizens, both through coverage of official statements and through feature articles and opinion pieces. An analysis of all surviving newspaper articles on AIDS published in one of Malawi's major newspapers, The Daily Times, found 8 articles on VCT in 2001 and 2002, with titles such as "AIDS and Us: Testing and HIV", "AIDS and Us: Living With HIV" and "AIDS and Us: What HIV Counseling Is" (Chisi 2001a, 2001b, 2001c). ${ }^{6}$ Newspapers are available in rural Malawi, and press coverage is mentioned in the earliest conversations about testing and treatment, which begin to appear in our ethnographic data at that time.

Malawi was one of the first two countries to receive support from the Global Fund. By late 2004 and early 2005 testing began to be available in the rural areas, first at district hospitals and then at clinics. Access expanded rapidly, such that by mid-2006 there were 325 facilities with the capacity to test for HIV and 1505 trained counselors (Republic of Malawi 2006: 20). The Ministry of Health initiated a "Testing Week" in 2006, during which testing was also available at an additional 324 temporary outreach sites (Republic of Malawi 2006, Table 5, p.21). The theme of the campaign was "Plan Your Future: Go for HIV Testing Today." (Republic of Malawi 2006).

The rationale presented in the planning documents for Testing Week was that it would be first, a gateway to treatment, and second, an opportunity to deliver prevention messages to those who were infected and those who were negative:

The benefits of knowing one's HIV sero-status are now well known and [more] easily accessible than at any other point in time since the epidemic was known in this country in 1985. HIV testing is an entry point to access highly active antiretroviral therapy if that person is found HIV positive and is eligible. Antiretroviral therapy has dramatically improved the quality and duration of life for many Malawians living with HIV and may also reduce the risk for transmission by decreasing the viral load. HIV testing also affords one an opportunity to access other key HIV and AIDS care, support and preventive services. (Republic of Malawi 2006:2)

\footnotetext{
${ }^{6}$ We are grateful to Milagros Vandemoortele and Davie Chitenje for copying all articles on AIDS that were published in Malawi's two major newspapers, The Daily Times and The Nation. The articles from the Daily Times were analyzed by Vandemoortele for a senior honors thesis in sociology at the University of Pennsylvania.
} 
At this time HIV prevalence in Malawi was approximately $12 \%$; thus the vast majority of Malawians were HIV-negative. Yet the benefits of testing for those who were not HIV-positive received short shrift in the document, which stated simply that:

For the majority ... who are not infected, HIV testing and counselling will assist in reducing risk behaviour for HIV infection (Republic of Malawi 2006: 26).

Along similar lines, in launching the Testing Week campaign, the Minister of Health said that "HIV/Aids prevention efforts could come to naught if people do not come forward for treatment because they do not know they carry the virus." That only $15 \%$ of sexually active Malawians knew their results, she added, "poses a great threat to prevention efforts..." (Mail and Guardian 2006). The educational material used to train counsellors for Testing Week also reinforced the message that "positives" should receive more attention than "negatives". (Ministry of Health 2007). ${ }^{7}$ As we discuss below, the prioritizing of "positives" over "negatives" has significant and probably unintended consequences for individual Malawians considering testing.

Despite the confident statements above, behind the scenes there is less robust certainty that testing should be a top priority for containing the epidemic. Within the research community there is no consensus on whether knowing one's serostatus changes risk behavior for the better: (for reviews, see Auerbach et al. 2005; Obermeyer and Osborn 2007; Yeatman 2007). Responding to an article in The Lancet that called for universal testing in developing countries (Bunnell and Chrutich 2008), James Shelton concludes that the effects of VCT on sexual behavior have been modest (Shelton 2008). There is also a vigorous debate at the international level over the modalities of testing: should it be initiated by providers as a routine part of health care or should it continue to be initiated by the individual? Those who advocate routine testing emphasize the importance of testing as a gateway to treatment for those who are positive, whereas those who oppose routine testing argue that it would overwhelm already-strained health facilities in poor countries, that it could intensify stigma and violence (again, a speculation that focuses on the positives), and that it violates a human right "not to know' one's status (for a review, see Bass 2006; for the social consequences of routine opt-out testing in Malawi, see Angotti et al. 2009).

In contrast to these debates in the international community, among policy makers in Malawi there seems to have been little controversy about the benefits of testing. The only hint of ambivalence about the value of testing that we have found are rumors that circulated among stakeholders that those who had learned from testing that they were

\footnotetext{
${ }^{7}$ A review of real-world testing initiatives in the developing world suggests that this is similar elsewhere: "Most people who test negative apparently get little or no counseling", which is consistent with evidence we present below (Shelton 2008:274).
} 
positive were then retaliating by deliberately infecting others; the National AIDS Commission and UNICEF-Malawi took this possibility seriously enough to commission a study (Dzilankhulani et al 2005; Morah 2007 ${ }^{8}$ ).

\section{Data}

In 1997 Watkins and several colleagues began a longitudinal research project, the Malawi Diffusion and Ideational Change Project (MDICP), on the role of social networks in influencing responses to the AIDS epidemic in rural Malawi. After the first wave of the core survey in 1998, the researchers had a great deal of quantitative data about the composition and structure of the social networks in which rural Malawians talked about AIDS. They had not, however, learned much about the content of the social conversations what people said to each other about AIDS or their strategies for avoiding infection and death - and semi-structured interviews conducted in 1999 to address these questions were disappointing. The researchers thus improvised. They asked several high school graduates who had worked as short-term survey interviewers for the MDICP and who lived in or near the sample villages to be participant-observers as they went about their daily routines. If they overheard anything concerning AIDS they were to make mental notes of what people said and did, and then write their recollections in commonplace school notebooks that evening or soon thereafter. It was emphasized that they were not to interview, but rather just to listen to the talk going on around them. Approximately one-third of the interactions recounted in the journals took place in public places such as markets or child health clinics, one third while in transit, on foot, by bus or by bicycle, and one-third in other locations. ${ }^{9}$

More than 900 journals, covering thousands of conversations, have been written by a total of 22 field assistants since 1999 and subsequently typed and coded. ${ }^{10}$ The field assistants' close networks, the ones in which they routinely spend most time, are homophilous in terms of social characteristics, as are close networks elsewhere (McPherson et al. 2001), but many of the conversations they overhear have a very diverse cast of characters. For example, the most prolific of the female field assistants is on many committees in her community and sometimes attends regional or national meetings of these groups; the male field assistants often hang out in a nearby trading center, at the bus stop or at a bar. The women write primarily about women's conversations, the men about

\footnotetext{
${ }^{8}$ The study found that the expectation that HIV positives who knew their status were a main driver of the epidemic was unsubstantiated (Morah 2007).

${ }^{9}$ In 2005, Patrick Gerland and Susan Watkins asked five of the field ethnographers to keep a log of their conversations for seven days. The log recorded where the conversation took place, the activity the participants were engaged in at the time, the duration of the conversation, and the number of participants.

${ }^{10}$ Exemplars of the journals are posted on the MDICP website, www.malawi.pop.upenn.edu, which also provides detail on the overall study.
} 
men's, reflecting the gendered interaction typical of the communities in which they live (Marshall 1970).

Nine female field assistants and thirteen males contributed to our corpus of texts, with three (two males, one female) contributing very frequently, 13 frequently, and six only occasionally. They write in English, a language learned in school, and use parentheses or carets $(<>)$ to set off their explanatory comments or untranslatable expressions in the local language. We have retained idiosyncrasies in grammar and spelling, although on occasion we insert obviously missing words in brackets or make minor grammatical changes in the interest of legibility. The excerpts used here have been anonymized to remove any identifying information, and the field assistants are given pseudonyms. Each excerpt is dated in year, month, day format (e.g. Alice 040611).

We have several caveats regarding this method. First, as in surveys, semi-structured interviews, and focus groups, we cannot draw a straight line between what people say and what they do. We believe that what people say to each other is different from what they say to an interviewer with a clipboard, but presentation of self is an issue in informal as well as formal settings. Second, we only know what the field assistants remembered and wrote down about what they heard. Third, because we left it up to the journalists to decide what a "conversation about AIDS" was, the journals include only what they considered to be "about AIDS" and of interest to us.

Field assistants were paid for each journal, so we were alert to the possibility of fakery. We have evaluated the journals in the light of other information (e.g. from the survey and the semi-structured interviews). In addition, because some of the more notorious characters in the area appear in the journals of more than one journalist, and some actors appear in more than one journal, we have examined internal and crossjournalist consistency. Most convincing, however, are the internal qualities of the journals, such as the relative absence of clichéd situations and characters (Kaler 2003). We (and other readers of the journals) are struck by their quality of verisimilitude. While only extended excerpts from many journals could make this point fully convincing, it is evident as one reads these journals that only a novelist as gifted as Dickens could have created such a variety of voices, situations, incidents, and viewpoints as have our multiple field assistants.

\section{Analysis}

To take on the complex task of quantifying uncertainty and ambivalence, we tallied all references to HIV testing in the coded journals and then coded these for descriptions of 
testing in either positive or negative terms. ${ }^{11}$ Non-judgemental remarks (such as "I heard there is testing at XYZ clinic") were not included. References were included in the category of goodness-of-testing if they met one of the following criteria:

1) A general statement (e.g. "It is good to have an HIV test before one marries").

2) A statement of the speaker's intention or desire to be tested.

3) An account of a third party who was tested, with a good outcome for that third party, whether the result of the test was positive or negative.

References were included in the category of badness-of-testing if they met one of the following criteria:

1) A general statement (e.g. "Anyone who goes for an HIV test is asking for trouble.")

2) A statement of the speaker's intention or desire not to be tested.

3) An account of a third party who was tested with a bad outcome for that party, whether the test result was positive or negative.

In accounts of extended conversations or complex interactions, each speaker was tallied only once for each sub-category of goodness or badness expressed during the conversation. For instance if Adam mentioned his cousin Farah, who was relieved and happy to have gotten a negative HIV test, twice over the course of a conversation, only the first reference to cousin Farah would be tallied. However, if Adam mentioned cousin Farah's experience and then later in the conversation expressed his own intention to be tested himself before he married his fiancée, both references would be tallied.

Of all the references tallied from the journals covering 1999-2005, 37\% referred to the goodness of testing and 63\% to the badness of testing. Between 2006 and 2009, 38\% referred to the goodness of testing and $62 \%$ to the badness, suggesting that this division of attitudes towards testing is stable over time.

Tables 1 and 2 below present the dominant themes, obtained by coding all references and then collapsing smaller codes into larger codes, until the point was reached at which further collapsing would lead to excessive vagueness. We have subdivided the table into columns for the journals from 1999-2005 and from 2006-2009, to check whether the persistence and distribution of the themes appeared to be stable.

\footnotetext{
${ }^{11}$ From this point onwards, we use the phrases "goodness of testing" and "badness of testing" rather than "positive" or "negative", to avoid confusion with seropositivity and seronegativity.
} 
Kaler \& Watkins: Asking God about the date you will die: HIV testing as a zone of uncertainty in rural Malawi

\section{Table 1: Why is HIV testing bad?}

\begin{tabular}{lcc}
\hline Theme & \multicolumn{1}{c}{ Percent of references expressing theme } \\
\cline { 2 - 3 } & $\mathbf{1 9 9 9 - 2 0 0 5}$ & $\mathbf{2 0 0 6 - 2 0 0 9}$ \\
\hline $\begin{array}{l}\text { 1. Testing positive will hasten } \\
\text { psychological deterioration and } \\
\text { death. }\end{array}$ & $46 \%$ & $41 \%$ \\
$\begin{array}{l}\text { 2. Clinic staff and/or the test itself } \\
\text { cannot be trusted }{ }^{12} \text {. }\end{array}$ & $21 \%$ & $11 \%$ \\
$\begin{array}{l}\text { 3. Testing is pointless if one is } \\
\text { already convinced of one's status. }{ }^{13}\end{array}$ & $21 \%$ & $32 \%$ \\
$\begin{array}{l}\text { 4. Testing will damage relations with } \\
\text { family members/other important } \\
\text { people. }\end{array}$ & $9 \%$ & $15 \%$ \\
\hline
\end{tabular}

\section{Table 2: Why is HIV testing good?}

\begin{tabular}{lcc}
\hline Theme & \multicolumn{2}{c}{ Percent of references expressing theme } \\
\cline { 2 - 3 } & $\mathbf{1 9 9 9 - 2 0 0 5}$ & $\mathbf{2 0 0 6 - 2 0 0 9}$ \\
\hline $\begin{array}{l}\text { 1. One can access antiretroviral } \\
\text { treatment and/or "live positively }\end{array}$ & $33 \%$ & $32 \%$ \\
$\begin{array}{l}\text { tests positive. } \\
\text { 2. It is generally good to know one's } \\
\text { status ("the truth about one's body.") }\end{array}$ & $30 \%$ & $28 \%$ \\
$\begin{array}{l}\text { 3. One should get tested before } \\
\text { marrying. }\end{array}$ & $21 \%$ & $18 \%$ \\
$\begin{array}{l}\text { 4. One can change one's behavior to } \\
\text { protect oneself if one tests negative. }\end{array}$ & $9 \%$ & $23 \%$ \\
\hline
\end{tabular}

${ }^{12}$ We interpret the question of trust as referring to concern that test results will not be kept confidential. Accounts of nurses and health assistants who gossip occur frequently in the journals, as do stories about people who seek health care far from home because they do not want the clinic staff to talk about them with neighbors. For instance, one journalist reported the conversation of a group of men denigrating the local testing facilities: We these days fear to go to the hospital ... because our doctors these days keep no secrets as they used to in the past. These days they are the ones discriminating [against] patients, and ... if they find a person with HIV, instead of keeping his or her secret, they are the ones on the forefront revealing people's secrets. We get such stories in the drinking joints, doctors pointing fingers to patients. (Frackson_060212)

${ }^{13}$ Being convinced of one's status without being tested usually comes through the form of "autobiographical diagnosis", in which consideration of one's own past behavior and the past behavior of sexual partners leads to the conclusion that one must be, or must not be, HIV-positive ([first author] 2004b; Santow, Bracher, and Watkins 2008).

14 "Living positively" refers to a constellation of behavior and consumption practices, such as exercise and eating lots of protein and vegetables, recommended for people who are HIV-positive but not yet afflicted with AIDS. The concept of "positive living" is a staple of AIDS education activities in Malawi. 


\section{The badness of testing}

What unites the themes in the "badness of testing" category is the presumption of a positive result if one were to be tested. Confirming this presumption by means of a test has several quite undesirable outcomes in addition to psychological and physical deterioration and untimely death: clinic personnel may not keep one's positive status a secret (there would be no problem if the test confirmed that one were negative); there is no point in testing if one already knows one's status (which, the speaker usually implies, is certain to be positive); and social relations will be disrupted (again, there would be no problem if the test result was negative).

One woman lays out the options that people in her village face:

You know the secret is that when a person's sexual behaviour is clean and good you go for voluntary counselling and testing, you do not doubt, hence you have all the hope that possibly the result can be on the safer side, but when you have a sexual partner [and] a lot of sexual relationships, you do not even think of going for the blood test for kachilombo [the HIV virus], you fear and have doubts, because you automatically know the chances are high of being positive [for] the kachilombo.

One of her friends immediately validates the first speaker's concerns, giving her reasons for not wanting the test:

Mrs L said "Eee! I cannot go for the blood test for kachilombo. Ee! I have had a lot of boyfriends, and all of them we were having unprotected sex, so I cannot go for the test. ... I fear being found positive, and having this status, I do not think that I can have freedom in this life, and it can be the end of the world. It is better to stay as I am”. (Daniel_06083)

The most often-cited reason for not testing is the emotional and physical deterioration expected to follow a positive test result.

[An acquaintance said] "Going for HIV tests is just the same as asking God about the date when you will die because after those tests, once you have got that infection, you do know yourself that you are going to die anytime, which is not good. I see that it is better to just live without knowing anything about that" (Diston_040319) 
This man, like others who speak of themselves as likely to be HIV-positive, is quite certain about the badness of testing: he speaks with conviction that confirming one's belief that one is HIV-positive will create lethal levels of anxiety, worry and fear, thus hastening inevitable death from AIDS. Other speakers are more ambivalent, such as the man quoted below who both wants and does not want to know his status:

Life is very important and enjoyable thing therefore it is not good to spoil it. What I am worrying about is that I don't know that I am free from it [HIV] and I am positive. I am worried because I had many sexual partners and I have slept with many women from different areas. I was thinking of going to the hospital for the blood test, but I am afraid. It can happen that I am HIV positive therefore I can commit suicide. I can use any chemical to spoil [end] my life [rather] than being a chronically ill patient for a long time like that woman I saw at the hospital. I don't want my parents and my wife busy looking after me for a long time when I will be on bed rest. (Alice_020710)

Other journal excerpts describe uncertainty about testing within communities: some individuals may claim to be certain that testing is bad, but others say that it is good. Below a field assistant's wife recounts a conversation among female relatives on the merits of testing:

My wife said that N. and Abiti M. said that it is not good to have VCT because you don't live happily as you do know that you are going to die of that AIDS anytime, and she said that sister H. said that it is good because you are told the truth about your health status and that she will go for VCT herself, and there's nothing wrong with VCT because when you are found either HIV positive or negative, you are given some advice about how you can live longer, and that when you are found HIV positive they do tell you that that is not the end of your life and tell you about how you can live so that you take a longer time before you die and that it still pains when you have been found HIV positive because you do really know that you are going to suffer anytime and that it is only good when you are found that you don't have that disease. (Diston_041115_1)

Many speakers assume that testing will only confirm what they feel already to be true: that they are HIV-positive. Suicide is the ultimate manifestation of the anxieties and worries provoked by a positive test result. Although the journals contain only two mentions of actual suicide attempts by people who have tested positive for HIV, the possibility of suicide is repeatedly invoked in conversation. 
One woman tells a journalist that she cannot live with the knowledge that she has HIV:

[She] said that testing for AIDS is a great mistake that she cannot do, because once she is found with HIV she will get worried and sad, so that she cannot live longer, but she can shorten her life by committing suicide in order to forget everything and avoid giving other people a job of caring for her when she is sick. ...It is better for her to live ignorant, without knowing the truth for she will live happy without worrying about anything (Patuma_060625)

Another young man, explaining his refusal to get tested, claims that he would rather suffer from AIDS without knowing the cause of his symptoms than be told that he is HIVpositive:

Don't you know that it is dangerous to get tested in your life? Like myself, I cannot go for testing. ... I cannot do that because I know I can commit suicide. ... If I don't know that I have HIV, I will be just living [and] if I begin suffering from AIDS I will still not know that this is AIDS. But if my relatives take me to the hospital and tell me that I have AIDS, I will ask them to buy [pesticide] for me to drink and die. (Alice_080725) ${ }^{15}$

The benefits of testing touted in official media and repeated in conversation - such as counseling and antiretrovirals - are balanced against the presumed consequences for future life and happiness. This calculus, however, is premised on the presumption that positive diagnosis is the most likely outcome of a test.

If all we knew about HIV prevalence came from the stories about testing which circulate in these rural communities we would assume that nearly everyone in Malawi is HIV-positive. The majority of the stories about people who get tested end with the subject of the story receiving a positive result, and sickness and death (whether self-inflicted or not) following in rapid succession. In the excerpt below a journalist is at a local sporting event when one of the spectators, described by the journalist as a chief, tells the others that he has to leave the game early, because he must go to a funeral in his village for a woman

\footnotetext{
${ }^{15}$ The link between positive test results and suicide is also invoked in public education aimed at raising awareness of prevention and treatment for HIV. In one AIDS-awareness drama a young man learns that his intended wife is HIV-positive. His parents refuse to let her visit their home, and she attempts suicide in despair, although her husband assures her that he will not abandon her. The young man's father receives his comeuppance when he too learns through testing that he has HIV, a result of his philandering. He kills himself on stage, and his wife has a heart attack from shock. This chain of catastrophes spiraling from a positive test result may not inspire a desire to be tested in audience members (Moloko 070615). In another drama, six people who test all learn that they are positive, and three of them carry out a suicide pact. (Moloko 060308)
} 
who has died of AIDS. In the chief's account the HIV test is the immediate precursor to rapid decline and death.

She [the woman who died] has died [of] AIDS related diseases. ... First she was diagnosed with $T B$ and she was treated. After she got cured things did not really improve for her. She stayed [healthy] only half a year ... then later things started to worsen again for her when she just started losing weight again but without any diagnosed disease. She went back to the hospital for a TB test again, they found out that it was negative.

Later on she decided to have a blood test for HIV/AIDS where it was found that she was HIV positive. Then from that time she has been suffering different kinds of diseases, today one and tomorrow another disease again, ranging from malaria, colds, open bowels, rashes on the skin, some swellings on the body and even open sores. People were still trying to give her different African medicine just for the sake of lessening the pain but it was not helping anything. Things were changing from bad to worse, to the extent that she was not moving and if she want to go out of the house she had to be carried, until she has passed away this afternoon. (Chikondi_050212)

The probability of deterioration and collapse after getting a positive test result dominates discussions of the badness of testing; however, the themes that did not emerge as major concerns are also worthy of note. In particular, stigma does not feature prominently. Some do worry about it: for example, one man, who did have a blood test, claimed before the test that if the results were positive he would change his name and go to live permanently in the large urban centre of Lilongwe, never returning to his home village (Patuma_050413). Another man said he would be isolated by his friends and unsuccessful with women:

Once people know that [a person] is HIV positive, they will stop chatting with him. He continued saying that he will fail to drink beer with his friends for they will isolate him and that all the girl friends he used to have sex with him will run away from him. (Patuma_050303) ${ }^{16}$

These statements are credible and moving. Yet across all the journals analyzed here only $9 \%$ say that not wanting relationships with other people to deteriorate is a deterrent to taking the test, contradicting the assumption in the literature that stigma is a powerful counter-incentive to testing and that testing must be "de-stigmatized" if it is to be successful. Moreover, we find little evidence in the journals of actual discriminatory

${ }^{16}$ See also BBC News 2005, MANET 2003, Rankin et al. 2005. 
behavior towards people with AIDS. The journals do not describe a caste of social pariahs with AIDS, and in fact contain many examples of normal social interaction with people who are known or suspected to be HIV positive; another project interviewed caretakers of people with symptoms of AIDS and found that neighbors visited to cheer up the patient and the caretaker (Chimwaza and Watkins 2004). Friends do advise one another not to have sex with so-and-so because, for example, a previous partner died of AIDS, but we consider this to be practical advice rather than an expression of revulsion.

\section{The goodness of testing}

The goodness-of-testing themes echo the messages in favor of VCT as articulated at the global level and disseminated in Malawi. These themes appear in radio and newspaper accounts of speeches by health professionals or representatives of NGOs and are delivered in person by paid health workers, often through "healthy talks" given at the maternal and child health clinics. Virtually all who speak on the topic in the journals say that following a positive result one must "live positively": do not worry; eat a balanced diet (especially vegetables); get exercise and continue working; do not have sex without a condom because if your partner is also infected you would be "adding viruses" to your body, which will hasten death. This is also accompanied by references to treatment. It is understood that the medicine is not a cure, but one will live longer, whether for only a few years or for as many as 10 or 20 .

This emphasis on "positive living" presumes, as did the majority of the "badness of testing results", that the most likely outcome of a test is a positive result. Between 1999 and $2005,33 \%$ of goodness-of-testing comments referred to treatment, which implies a positive test result, while only $9 \%$ articulated the possibility of a negative test result. However in the later diaries the possibility of testing negative becomes more prominent, as $23 \%$ of comments refer to preserving one's negative status as a reason to test, an indication that perceptions of VCT may be changing.

One woman reassures her friend that she did the right thing by getting tested, unlike other people who refuse to acknowledge the likelihood that they have HIV:

"My sister, it is better for you because you know in your body there is that virus. ... Had it been that you were living without going to the VCT clinic, you could have already died. Now you should thank God for giving you the idea of going to the VCT centre, that is why you are alive up to this date". [The woman who was tested] said "What you are saying is true. My late husband was afraid to go for the blood test, and I do think that's why he died. I advise my children to go for blood testing, so that they should know how they are [know their serostatus] 
Kaler \& Watkins: Asking God about the date you will die: HIV testing as a zone of uncertainty in rural Malawi

before they start to suffer from AIDS. I know that it's better for a person to go for blood testing before he or she starts to suffer from it". (Anna_061108)

Another conversation, recorded in the same month, reveals more ambivalence about the goodness of testing, as one man promotes testing as a way to access treatment while his friend remains skeptical:

"I tell you, a lot of people have been saved by going to the VCT centres, they are having a better life now than the time they didn't go for a test."

"What do you mean, brother?... Once you have been found with AIDS what you have to know is that you are dead and no doubt about that," emphasized B.

"You know what B, being positive does not mean you will die tomorrow or today, no! It is not the end of your life, once you have been found positive with these people, what they do is that they examine your health and if you are okay you start taking ARVs. So you see ... [in comparison] with someone who has not yet tested and does not know his or her status in terms of HIV, the one tested is on the better side", explained $A$.

"Still, I prefer not being tested, it's not good to know your blood status ... Once you have been found with AIDS ... you cannot have peace of mind at all and I can give you examples of that, of people who have been tested and found positive are the ones who die faster than it could have been if they were not tested," challenged $B$.

"Brother, the point is that when you have been tested and found positive, you start taking ARV medicine so ... you can see how advantaged this person [who has tested] will be", [said A]. (Trueman_061102)

The prevailing assumption in the conversation above, that HIV tests always produce positive results, may be bolstered in part because VCT counselors are perceived to devote more attention to those who receive positive test results, so that proportionally more of their time is taken up with people who learn that they have HIV. This difference between the positives and negatives is evident in the following excerpt, in which a young man is talking about going with a friend to be tested: the friend was positive, he himself was negative.

[He] laughed and said that when the results were out at the same day within a short period of time [his] friend was found positive and him negative and they were all given advices. He said that the advice his friend was given was that he should make sure to be courage for a lot of people are living positive but still they live happily and still their lives goes on for having the positive is not the end of life and he was 
also advised to go and be eating well balanced diet including vegetables and abstain still if not he may be using the condoms when sleeping with sexual partners. [He] went on saying that [his friend] was thanked by the doctor for taking such a great challenge of visiting there at Macro in Blantyre to have the blood status and happy that he had known his body status and he can now live further by protecting himself from avoiding plain sex, smoking and drinking beer and avoid over working.

....[He] said that he [himself, who tested negative] was not given much advice but he was only told to continue caring himself, avoid doing plain sex and always have the prospective goal in his life and make sure to fulfill that by taking care for himself because AIDS is still looking for the negative ones and if not careful he may found having it either by careless like sharing the needle or razor blade, teeth brush with someone having the virus and cut himself/herself and you use it and cut yourself too or chose to have plain sex than using the condom. (Simon 040203)

In the following excerpt, we again see the language of media messages, but this time, and untypically, not to justify testing but to justify the disclosure of HIV-positive test results at funerals. The speaker takes the position that testing is a good thing, as it will lead to more disclosures at funerals of the cause of death, serving as a warning to other people to mend their ways. She buttresses her argument with reference to the media-disseminated government line on the goodness of testing and the importance of openness about serostatus. Again, her argument implies that a positive result is the most likely outcome of testing:

A. told them that she had gone to the Kalembo Health Centre and that she saw a team of some people who were also doing the same work of taking blood tests. When A. said this, Abiti F said that those people who are taking the blood tests are doing well because everybody will know that he or she has got AIDS and that Bingu (Malawi president) has said that there should be transparency in saying the truth about what one is suffering from and [when someone] has died of AIDS they have to be saying that he/she has died of AIDS, and ... they don't have to be hiding the truth about that. (Diston_041115_1)

While it is not surprising that respondents in a formal interview setting would repeat messages from media campaigns, it is more noteworthy when the standard phrases of prevention and treatment programs are used in everyday conversations with peers. 


\section{When testing is on offer}

Talk about testing is very different from behavior when testing is actually offered, however, rather than being hypothetical. Despite the predominance of badness-of-testing themes in the journals, despite the fears of psychological deterioration should one test positive, despite the depressing stories of people who got tested and died miserably, when respondents in the 2004 MDICP survey sample were provided the opportunity to be tested for HIV in their homes, 91\% agreed (Obare et al. 2008; Angotti et al. 2009). Indeed, when the field assistants were working as temporary interviewers they were approached by acquaintances who had not been tested because they were not in the survey sample. ${ }^{17}$ Rather than hostility towards the tests, which might be expected given the apparent connection between testing, positive results, distress and death, the most common query was whether MDICP could come to the speaker's village and offer tests there. One field assistant who encountered several curious people at a sports match reported that he was asked:

"Can't you ask for us just to have people in our village tested because I heard last time you came to the villages people were having advance [the advantage] of having their blood tested?"

I paused for a while and answered that those people who were those people who were tested are the ones in our books [the records of MDICP] as I said it's not all the people who were tested and it is impossible to come to a certain village only to test people's blood, that will be out of our programmes and the only thing I can advise is tell the people in the villages to go for HIV test at the different hospitals in the country and other VCT centres [so that] they will knew their blood status. One of them answered "I feel that a lot of people feel shy and fear to go to the hospital for blood test, and moreover with this money crisis no one from the village can [afford] money for transport only for blood test I guess. As a result the disease is spreading rapidly among us". (Chikondi_050212)

The same field assistant, while in a shop in the local trading centre, encountered some people who recognized him from his travels around the area on behalf of the MDICP Survey. When they called him over he was nervous at first and concerned that he might be subject to criticism, but relaxed when it became clear that his interlocutors wanted to ask for more testing in their villages. They did so by invoking the dominant themes in goodness-of-testing messages:

\footnotetext{
${ }^{17}$ It is worth noting that no monetary or material reward was given to those who were tested. The only possible incentive for participating in the testing was the chance to learn one's HIV status.
} 
"Because before you came, ... [n]obody was daring in our village to have enough courage to go to the hospital to have his or her blood tested, for different reasons. As a result, people [did not know] in the village [who] is infected, hence the spread of the disease was on the rise".

I asked him ... "Are you now a position to know who is infected in the village and if so how?" [He answered] "first of all, some of the people who were found with the disease are revealing it on their own that they will never do any misbehaviour, since they now know their blood status that they are positive.

"And those maybe those that are still not yet infected they are saying the same things, that they have completely changed their behaviour from the day they get their results from you, hence you can see that [testing] will make the whole village to be clean, with all the people changed their behaviour".

He continued saying "Next time you come you will recognize that everybody will be willing to have his or her blood tested since they have seen the advantage of having one's blood tested to know one's status on Edzi (HIV/ AIDS)". (Chikondi_041223)

Asking for testing to be available and actually going for a test are not necessarily congruent. Yet the expressed interest in testing is corroborated by the very high acceptance rates in those villages where the MDICP survey did offer HIV tests $-95.0 \%$ among females and 96.2\% among males in 2004 (Obare et al. 2008: 10 [Table 2]).$^{18}$ What is even more relevant however, is willingness to learn the results of the test. In the 2004 MDICP round results were not available immediately and sometimes not for weeks; nonetheless, $69 \%$ of those tested returned to collect their results (Thornton 2008: 1838). If someone genuinely did not want to know their test results it would have been easy to not return to collect them. Indeed, returning to find out results was more difficult than not returning, given the opportunity costs of time spent waiting at the mobile post-counseling sites.

The contradiction between expressed attitudes and actual behavior with respect to testing suggests not so much a rejection or a wholehearted embrace of testing as it suggests ambivalence in perceptions of the badness and goodness of testing, ambivalence that in the case of the MDICP survey's testing was overcome. ${ }^{19}$ In addition, the presumption that the

\footnotetext{
${ }^{18}$ Refusal rates were considerably higher in the nationally representative sample of the Malawi Demographic and Health Survey, also conducted in 2004. This may be in part because the 2004 round of the MDICP was the fourth round, so respondents were familiar with the survey team.

${ }^{19}$ In 2004 the MDICP conducted a field experiment to see whether modest incentives and accessibility would overcome reluctance to learning one's serostatus (Thornton 2008). After pretest counseling, respondents could participate in a lottery. The outcomes were vouchers, to be redeemed when results were collected. The amounts ranging from 0 to US $\$ 3.00$, with the average voucher equivalent to a day's wage in the MDICP sites. Only $34 \%$ of those who received a zero-valued voucher returned for their results, but the lowest amount of incentive (approximately one-tenth of a day's wage) doubled that share. Distance also mattered. Mobile clinics were randomly placed, $95 \%$ of these tested living no further than $5 \mathrm{~km}$. from a mobile clinic and the average distance
} 
results of a test are likely to be positive contrasts with the story told by biological markers of HIV in the villages covered by MDICP survey.

In the survey interview that preceded the HIV test in 2004, respondents were asked what they thought their chance was of being currently positive as well as their expectations of infection in the future. Of the women who reported a high likelihood that they were already HIV+, 92\% were incorrect; of the men, $87 \%$ were incorrect (Anglewicz and Kohler 2009). Of the wives who reported a high likelihood that their husband were HIV+, $89 \%$ were inaccurate; of the husbands who reported a high likelihood that their wife was HIV+, 91\% were wrong. While 2004 MDICP HIV testing found actual HIV prevalence to be approximately $7.0 \%$ across all three fieldwork sites, female and male MDICP respondents in 2004 estimated an average of $42 \%$ and $38 \%$ infection, respectively. In other words, the most likely outcome of a test was a negative result, although one would never know that from reading what was said in conversations on testing.

\section{Discussion}

Our consideration of testing-talk in the journals brings out two main themes. One is the disjuncture between official expressions of the unqualified goodness of testing and local expressions of ambivalence and uncertainty, the other is the widespread presumption of a positive result as the outcome of testing.

Why do people expect that if they are tested they will learn they are positive? We believe there are two explanations. First, the advocates of testing assume, explicitly or implicitly, that it is the positives, not the negatives, who will benefit from testing. Second, and we think most important, is that most people vastly overestimate the transmissibility of HIV, and hence the likelihood that they themselves are infected. We discuss each in turn.

The discourse of VCT advocacy: Advocates promote VCT for everyone, infected and uninfected. Yet by using the phrase "live positively" in public campaigns such as Malawi's Testing Week, they signal that they are talking to the infected. Moreover, when advocates argue that testing is important for prevention, they are also signaling that VCT is particularly important for the infected, that it is their sexual behavior that is relevant. This emphasis on the relatively rare positive diagnoses resulting from testing reinforces the common belief that HIV is not only ubiquitous but also inevitable for anyone who has ever had sexual contact with an infected person.

Overestimation of the transmissibility of HIV: MDICP survey respondents were asked what they knew about the epidemiology of HIV. Since the first survey round in 1998

was $2 \mathrm{~km}$. Living over $1.5 \mathrm{~km}$ from the mobile clinic reduced attendance by $6 \%$. At the time of the 2004 round, the nearest fixed health facilities to the MDICP study villages were 20 to $40 \mathrm{~km}$ away (for a full description of the experiment, see Thornton 2008). 
virtually all knew that a healthy person could be HIV-positive and that HIV was sexually transmitted (for women the main concern was that they would get AIDS from their spouse, for men their main concern was infection from an extramarital partner [Smith and Watkins 2005]).

Yet in response to a question that was meant to get at their understanding of HIV transmission probabilities, most were wrong. When asked what the likelihood of infection was due to a single act of unprotected intercourse with an infected person, $97 \%$ of males and $95 \%$ of females said this likelihood was "certain" or "highly likely." (Anglewicz and Kohler 2009). Actual transmission probabilities per sexual act, of course, are far lower. A recent meta-analysis of epidemiological studies that estimated transmission probabilities per act of unprotected intercourse with an HIV-positive partner found that for low-income countries the likelihood was well below a 1 percent chance per act (Boily et al. 2009). ${ }^{20}$ The overestimation is not unique to Malawi - it was also found in a study of Canadian college students (Knauper and Kornik 2004) and elsewhere in sub-Saharan Africa (Fylkesnes and Siziya 2004). Nor is it surprising, since the template for understanding HIV is based on other sexually transmitted infections for which transmission is orders of magnitude higher, such as gonorrhea (Santow, Bracher, and Watkins 2008).

\section{Conclusion}

Rural Malawians' uncertainty about testing for HIV is in stark contrast to the public certitude of those who determine policy internationally and in Malawi. Policy documents are unambiguous in declaring that testing is a good thing: knowing one's HIV status is said to enhance the ability of people to protect others from infection, to protect themselves from further infection through "mixing viruses", to living positively, and as a gateway to treatment. But for many rural people testing is fraught with danger. Some, of course, believe that they are negative - they know what risky sex is, they may have never had even one act of risky sex, and they have good reason to believe their partner is negative also. For these testing would be uncomplicated were it not for the costs of time and travel to reach a health facility that offers testing. Others consider their own behavior and the behavior of their partner, and conclude that they must already be on the road to AIDS. For

\footnotetext{
${ }^{20}$ Female-to-male transmission was 0.38 percent per act; male-to-female transmission was 0.30 percent per act (Boily et al. 2009, Table 1:120). ${ }^{20}$ Transmission probabilities are higher in some circumstances, such as the presence of sexually transmitted infections (especially genital ulcer disease), lack of male circumcision, and exposure to commercial sex work. When these were taken into account there was no statistically significant difference in the risk of infection of males and females. Even when such factors act in combination, the probabilities of transmission are still far lower than most other sexually transmitted infections (Santow, Bracher, and Watkins 2008).
} 
them the prospect of removing any uncertainty is frightening, and reason enough for not seeking testing (see also Sherr et al. 2007, for Zimbabwe).

The arrival of AIDS in rural Malawi provoked uncertainty about the feasibility of preventing death from this stunning new disease (Kaler 2004a). Without much help from policy and programs they turned instead to their friends, relatives, and neighbors to formulate and evaluate what might be feasible and effective strategies of prevention (Watkins 2004). By now their uncertainty is largely resolved: AIDS can in principle be avoided, even if the effective practices are still considered very difficult. This suggests that current ambivalence about testing may come to be resolved as well, that rural Malawians may convince each other that they would benefit from learning their body's status.

We uncovered some hints that this ambivalence in the discourse about testing may be diminishing. We decomposed all the journals into those written between 1999 and 2005 and those written between 2006 and 2009 after testing became an actual rather than a hypothetical opportunity. Although the predominant attitude towards testing was negative in both periods, the proportion of participants who said that testing was good because one could protect one's health after testing negative went from $9 \%$ of all goodness-of-testing responses to $23 \%$. This may reflect a gradual realization that any individual who tests is much more likely to be negative than positive, a realization that is perhaps the result of the increasing number of Malawians who have courageously sought testing and found, to their surprise and delight, that they were HIV negative, and then spread the good news to their friends, relatives and neighbors.

The process of change might occur more rapidly were policy makers to be more knowledgeable about and responsive to how their messages are received by the targets of their efforts - why indeed would someone want to have an HIV test when misconceptions about the basic epidemiology of HIV, as well as the "positive living" rhetoric of HIV advocacy, associate VCT with learning one is positive? Why would one want to learn that they can expect a painful death from an incurable disease, brought upon them by their own actions or those of an intimate partner? Given this conflation of testing and a positive HIV diagnosis, what is remarkable is not that most people in rural Malawi do not avail themselves of it, but that so many overcome their profound misgivings and learn their body's status. 


\section{References}

Anglewicz, P. and Kohler, H.P. (2009). Overestimating HIV infection: The construction and accuracy of subjective probabilities of HIV infection in rural Malawi. Demographic Research 20(6):65-96. doi:10.4054/DemRes.2009.20.6.

Angotti N., Bula, A., Gaydosh, L., Kimchi, E., Thornton, R., and Yeatman, S.E. (2009). Increasing the Acceptability of HIV Counseling and Testing with Three C's: Convenience, Confidentiality and Credibility. Social Science \& Medicine 68: 226370. doi:10.1016/j.socscimed.2009.02.041.

Angotti, N. (2010). Testing differences: The implementation of western HIV-testing norms in sub-Saharan Africa. [Ph.D thesis], Department of Sociology, University of Texas-Austin.

Auerbach, J.D., Hayes, R., and Kandathil, S. (2005). Overview of effective and promising HIV prevention interventions. In Ross, D.A., Dick, B., and Ferguson, J. (eds.). Preventing HIV/AIDS in young people: A systematic review of the evidence from developing countries. UNAIDS Inter-agency Task Team on Young People (World Health Organization: Geneva, 2006). http://www.who.int/child-adolescenthealth/publications/ADADH/ISBN_92_4_120938_0.htm

Banda, A.K. (2001). Press statement by Minister of Health and Population Honourable Alekeke K. Banda on the occasion of World Population Day 2001 Lilongwe: Government of Malawi.

Bass, E. (2006). UNAIDS and WHO set controversial course for HIV testing. The Lancet: Infection 6:760.

BBC News (2005). "Mums-to-be shun Malawi HIV tests (May 17 2005)". http://www.aegis.com/news/bbc/2005/BB050512.html.

Boily, M-C., Baggaley, R.F., Wang., L., Masse, B., White, R.G., Hayes, R., and Alary, M. (2009). Heterosexual risk of HIV-1 infection per sexual act: systematic review and meta-analysis of observational studies. The Lancet 9:118-129. doi:10.1016/S14733099(09)70021-0.

Bunnell, R. and Churich, P. (2008). Universal Testing and counseling in Africa. The Lancet 371:2147-2148. doi:10.1016/S0140-6736(08)60929-0.

Chimwaza, A. and Watkins, S. (2004). Giving care to people with symptoms of AIDS in rural sub-Saharan Africa. AIDS care 16(7): 795-807. doi:10.1080/09540120412331290211. 
Kaler \& Watkins: Asking God about the date you will die: HIV testing as a zone of uncertainty in rural Malawi

Chisi, JE. (2001a). "AIDS and us: Testing and HIV" May 16, 2001. The daily times [Malawi]. May 162001.

Chisi, JE (2001b). "AIDS and us: Living with HIV". The daily times [Malawi]. June 27 2001.

Chisi, JE (2001c). "AIDS and us: What HIV counseling is". The daily times (Malawi). November 212001.

De Cock, K.; Marum, E., and Mbori-Ngacha, D. (2003). The Lancet 362(9398):1847-1849. doi:10.1016/S0140-6736(03)14906-9.

Dzilankhulani, A., Matamba, S., and Casela, C. (2005). Are people aware of their positive $H I V$ serostatus responsible for transmitting the virus in Malawi?. Lilongwe: National AIDS Committee [Malawi]/UNAIDS.

Fylkesnes, K. and Sziya, S. (2004). A randomized trial on acceptability of voluntary HIV counselling and testing. Tropical medicine and international health 9: 566-572. doi:10.1111/j.1365-3156.2004.01231.x.

Global HIV Prevention Working Group (GHPWG) (2004). HIV prevention in the era of expanded treatment access. Bill \& Melinda Gates Foundation and the Kaiser Family Foundation.

Kaler, A. (2003). 'My girlfriends could fill a Yanu-Yanu bus': Rural Malawian men's beliefs about own serostatus. Demographic Research Special Collection 1-11: 349 372. doi:10.4054/DemRes.2003.S1.11.

Kaler, A. (2004a). AIDS-talk in Everyday Life: The Presence of HIV/AIDS in Men's Informal Conversation in Southern Malawi 1999-2001. Social Science and Medicine 59: 285-297. doi:10.1016/j.socscimed.2003.10.023.

Kaler, A. (2004b). The moral lens of population control: condoms and controversies in southern Malawi. Studies in family planning 35(2): 105-115. doi:10.1111/j.17284465.2004.00012.x.

Kaler, A. (2006). They see money and they think it's life: money, modernity and morality in two sites in rural Malawi. Journal of southern African studies 32(2): 335-349. doi:10.1080/03057070600656333.

Karim, S.A., Karim, Q.A., and Baxter, C. (2003). Antiretroviral therapy: challenges and options in South Africa. The Lancet 362(9394): 1499. doi:10.1016/S01406736(03)14700-9. 
Knauper, B. and Kornik, R. (2004). Perceived transmissibility of STIs: lack of differentiation between HIV and chlamydia. Sexually transmitted infections 80:74. doi:10.1136/sti.2003.007005.

Kohler, H-P., Behrman, J., and Watkins, S.C. (2007). Social networks and HIV/AIDS risk perceptions. Demography 44(1): 1-33. doi:10.1353/dem.2007.0006.

Mail and Guardian (2006). "Malawi launches campaign to promote HIV testing". July 17 2006. http://www.mg.co.za/articlepage.aspx?area=/breaking_news/breaking_news africa/\&articleid $=277809$, accessed 27 November 2008

MANET (2003). Voices for equality and dignity: research report. Lilongwe, July 182003.

Marshall, G. (1970). In a world of women: Field work in a Yoruba community. In: Goode, P. (ed.). Women in the field. Chicago: Aldine: 165-191.

McPherson, M., Smith-Lovin, L., and Cook, J. (2001). Birds of a feather: Homophily in social networks. Annual Review of Sociology 27: 415-444. doi:10.1146/annurev.soc.27.1.415.

Ministry of Health, Republic of Malawi (2007). HIV testing and counseling: Training for site counsellors. Participant's manual, version 3.0, June 2007. Lilongwe: Ministry of Health, Republic of Malawi.

Morah, E. (2007). Are people aware of their HIV-positive status responsible for driving the epidemic in sub-Saharan Africa? The case of Malawi. Development Policy Review 25(2): 215-242. doi:10.1111/j.1467-7679.2007.00367.x.

Obare, F., Fleming, P., Anglewicz, P., Thornton, R., Martinson, F., Kaputaka, A., Poulin, M., and Watkins, S. (2008). Acceptance of repeat population-based voluntary counseling and testing for HIV and the socio-demographic variations in HIV incidence in rural Malawi. Sexually transmitted infections 85(2): 139-144. http://sti.bmj.com/cgi/rapidpdf/sti.2008.030320v1.pdf. doi: 10.1136/sti.2008.030320.

Obermeyer, C.M. and Osborn, M. (2007). The utilization of testing and counseling for HIV: A review of the social and behavioral evidence. American Journal of Public Health 97: 1762-1774. doi:10.2105/AJPH.2006.096263.

Rankin, S.H., Lindgren, T., Rankin, W.W, Ng'oma, J. (2005). Donkey work: Women, religion, and HIV/AIDS in Malawi. Health care for women international 26: 4-16. doi:10.1080/07399330590885803.

Republic of Malawi (n.d.). Malawia's co-ordinated country proposal to the Global Fund for HIV. Tuberculolsis and Malaria. Lilongwe: Government Printers 
Kaler \& Watkins: Asking God about the date you will die: HIV testing as a zone of uncertainty in rural Malawi

Republic of Malawi (2006). National HIV testing and Counselling Week 17-22 July: Technical report. Lilongwe: Government Printers.

Santow, G., Bracher, M., and Watkins, S. (2008). Implications for behavioural change in rural Malawi of popular understandings of the epidemiology of AIDS. Paper presented at the IUSSP Seminar on Potential and Actual Contributions of Behavioural Change to Curbing the Spread of HIV, Entebbe, Uganda, 18-20 February.

Shelton, J.D. (2008). Counseling and testing for HIV prevention. The Lancet 372: 273-275. doi:10.1016/S0140-6736(08)61091-0.

Sherr, L., Lopman, B., Kakowa, M., Dube, Sabada., Chawira, G., Nyamukpa, C., Oberzaucher, N., Cremin, I., and Gregson, S. (2007). Voluntary counselling and testing: uptake, impact on sexual behaviour, and HIV incidence in a rural Zimbabwean cohort. AIDS 21: 851-860.

Smith, K. and Watkins, S (2005). Perceptions of risk and strategies for prevention: Responses to HIV/AIDS in rural Malawi. Social science and medicine 60:3 649660 .

Swidler, A. and Watkins, S. (2007). Ties of dependence: AIDS and transactional sex in rural Malawi. Studies in family planning 38 (3): 147-162. doi:10.1111/j.17284465.2007.00127.x.

Thornton, R. (2008). The demand for and impact of learning HIV status. American Economic Review 98 (55): 1829-1863. doi:10.1257/aer.98.5.1829.

UNAIDS/WHO (2004). UNAIDS/WHO Policy statement on HIV testing. http://www.who .int/rpc/research_ethics/hivtestingpolicy_en_pdf.pdf

UNAIDS (2008). Testing policy and practice. http://www.unaids.org/en/PolicyAnd Practice/CounsellingAndTesting/default.asp

Watkins, S. (2004). Navigating the AIDS epidemic in rural Malawi. Population and Development Review 30(4): 673-705. doi:10.1111/j.1728-4457.2004.00037.x.

World Health Organization (2007). Towards universal access: Scaling up priority HIV/ AIDS interventions in the health sector. Progress report. Geneva, Switzerland: World Health Organization

Yeatman, S. (2007). Ethical and public health considerations in HIV counseling and testing: What do we know and what should that mean for policy?. Studies in Family Planning 38(2): 271-278. doi:10.1111/j.1728-4465.2007.00139.x. 